\title{
The potential carcinogenic risk of tanning beds: clinical guidelines and patient safety advice
}

\author{
This article was published in the following Dove Press journal: \\ Cancer Management and Research \\ 28 October 2010 \\ Number of times this article has been viewed
}

Mette Mogensen'

Gregor BE Jemec ${ }^{2}$

'Department of Dermatology, Gentofte Hospital, Hellerup, Denmark; 2Department of Dermatology, Roskilde Hospital, Health Sciences Faculty, University of Copenhagen, Roskilde, Denmark
Correspondence: Mette Mogensen Department of Dermatology, Gentofte Hospital, Niels Andersensvej 7, DK-2900 Hellerup, Denmark

$\mathrm{Tel}+4561721762$

Fax +45397716

Email mogensen.mette@gmail.com
Introduction: In 2009, the WHO listed ultraviolet (UV) radiation as a group 1 carcinogen. In spite of this, each year, millions of people tan indoor in Western countries. The aim of this review is to summarize evidence of tanning bed carcinogenesis and to present guidelines for use of tanning beds and patient safety advice.

Methods: A narrative review of the literature was conducted based on both PubMed and Medline searches and on literature review of the retrieved papers.

Results: Use of indoor tanning beds represents a significant and avoidable risk factor for the development of both melanoma and nonmelanoma skin cancers. Frequent tanners are more often adolescent females. Tanning beds have additional potential adverse effects such as burns, solar skin damage, infection, and possibly also addictive behavior.

Discussion: The effort in preventing UV light-induced carcinogenesis should currently be aimed at developing new strategies for public health information. Tanning beds are one preventable source of UV radiation. In the majority of people solar UV radiation continues to be the major factor and therefore anti-tanning campaigns must always include sunbathers.

Keywords: tanning beds, skin cancers, melanoma, nonmelanoma

\section{Introduction}

Nowadays, a pale yet healthy skin is not always considered desirable and beautiful, particularly not by young Caucasian women. ${ }^{1-5}$ This desire to acquire a tan for cosmetic purposes has led to the development of a large indoor tanning industry, particularly in Western countries, and in the US alone, an estimated 30 million people tan indoors annually. ${ }^{6,7}$ The use of tanning beds/sunbeds continues to increase in popularity, ${ }^{6,8}$ which is of particular concern due to the carcinogenic potential of the ultraviolet (UV) light emitted by tanning beds. UV light is electromagnetic radiation with a wavelength shorter than that of visible light in the range $10-400 \mathrm{~nm}$. UV light is divided into three categories: UVA (400-320 nm), UVB (320-280 nm), and UVC (280-100 nm). The UV light emitted in tanning beds is mainly UVA (around 95\%-99\%) and UVB (around 1\%-5\%). ${ }^{6,9}$ The primary source of UV radiation in majority of the population continues to be solar UV radiation, but there is, as may be intuitively suspected, a high correlation between tanning bed use and sunbathing. Disentangling the two risk factors would allow a more targeted approach to reducing UV exposure in the population and should be a major issue for anyone genuinely concerned with public health. This review is however focused on carcinogenic and other effects on the skin caused by tanning bed UV radiation and how to advise patients about indoor tanning. 
To further complicate the issue, studies have suggested that it is not even the tan itself that promotes tanning as ardent tanners display addictive behavior. ${ }^{10,11}$ It has also been suggested that the source of addiction is chemical and amenable to pharmacologic intervention. ${ }^{12}$ Consequently, knowledge of the adverse effects of tanning is not enough to modify behavior. ${ }^{13}$

\section{Methods}

A narrative review of the literature was conducted based on both systematic PubMed and Medline searches in spring 2010 using the following MESH terms and words: tanning bed, sunbed, indoor tanning, nonmelanoma skin cancer, cutaneous malignant melanoma, burns, UV radiation, and related terms, and a review of the references of retrieved papers was done.

\section{UV carcinogenesis}

Experimental studies clearly demonstrate the potential carcinogenic effect of both UVA and UVB, ${ }^{14-17}$ though experimental studies which failed to identify UVA as a risk factor of melanoma were also found..$^{18}$ This understanding of UV-induced carcinogenesis forms a cornerstone of current efforts to curb the surge of skin cancer.

\section{Tanning beds and skin cancer}

Tanning bed lamps that produce higher levels of UVB to mimic the solar spectrum and speed the tanning process are popular. ${ }^{6}$ Indoor tanning beds can be found in private homes, fitness clubs, recreational facilities, and beauty salons. ${ }^{19}$ A large English survey from 2010 found that approximately a quarter of children (11-17 years) had used a tanning bed device at home and that $25 \%$ had used tanning beds unsupervised in tanning salons or gym centers. ${ }^{20}$ In 2000 , there were 2.8 million cases of squamous cell carcinoma (SCC), 10 million cases of basal cell carcinoma (BCC), 200,000 cases of malignant melanoma (MM), and 65,000 melanoma-associated deaths worldwide. ${ }^{21} \mathrm{UV}$ radiation exposure is the predominant environmental risk factor for melanoma. ${ }^{22} \mathrm{~A}$ substantial and growing body of evidence indicates that UV radiation emitted by the lamps used in tanning beds may damage the skin leading to premature aging $^{23-27}$ and lead to an increased risk of developing both nonmelanoma skin cancer ${ }^{6,28-32}$ and cutaneous MM., , 22,33-42 $^{-1}$ This is in good agreement with the classification of UV radiation as a group 1 carcinogen (carcinogenic to humans) by the World Health Organization (WHO) in 2009. ${ }^{43}$ In a population-based case-control study from 2002, the overall use of tanning devices was associated with the odds ratios (OR) of 2.5 (95\% confidence interval (CI): 1.7-3.8) for SCC and 1.5 (95\% CI: 1.1-2.1) for BCC. Adjustment for history of sunburns, sunbathing, and sun exposure did not affect the results. ${ }^{28} \mathrm{~A}$ previous study did not show this correlation; however, this study had no quantitative measure of UV exposure, and the study subjects had a low prevalence of tanning bed use. ${ }^{44} \mathrm{~A}$ similar population-based case-control study from 2000 evaluated the association between tanning bed use and MM. A significantly elevated OR for developing MM after regular exposure to tanning beds was found when adjusted for hair color, raised nevi, skin type, and number of sunburns; OR was 1.8 (95\% CI: 1.2-2.7). The OR was higher in individuals younger than age 36 years (adjusted OR: 8.1; 95\% CI: $1.3-49.5$ for regular versus never use). ${ }^{34}$ In a large Scandinavian study, use of tanning beds more than once per month was associated with a statistically significant $55 \%$ increase in MM risk. ${ }^{45}$ The Australian Melanoma Family Study, a multicenter, population-based, case-control family study, showed in 604 cases diagnosed between ages 18 and 39 years and 479 controls the OR for melanoma associated with ever use of sunbed was 1.41 (95\% CI: 1.01-1.96) and 2.01 (95\% CI: $1.22-3.31$ ), respectively, for more than 10 lifetime sessions. Among those who had ever used a sunbed and were diagnosed between 18 and 29 years of age, three-quarters $(76 \%)$ of melanomas were attributable to sunbed use. ${ }^{46}$ First exposure to sunbeds before 35 years of age significantly increased the risk of melanoma, based on seven informative studies (summary relative risk (RR) 1.75; 95\% CI: $1.35-2.26) .{ }^{41}$ In this large systematic review based on 19 informative studies, ever use of tanning beds was also positively associated with melanoma (summary RR, 1.15 ; $95 \%$ CI: $1.00-1.31$ ), although there was no consistent evidence of a dose-response relationship. Not all studies demonstrated an increased risk of MM in tanning bed users. Three studies demonstrated increased RR for SCC. These studies did not support an association with BCC. The limited evidence for a positive association between indoor tanning and BCC can be ascribed to the inability to account for total dose of UV radiation to the skin in these studies. Based on the above figures, it is of some concern that around $50 \%$ of girls aged 15-17 used tanning beds regularly in some areas in the $\mathrm{UK} .{ }^{20}$ It is however complicated to separate the carcinogenic effects of solar and artificial UV radiation as most tanning bed users with skin cancer are also frequent sunbathers, have more sun-sensitive skin, and have had more painful sunburns than nonusers. ${ }^{28}$ To adjust for sun exposure, confirm doseresponse relationship, and examine the different tanning 
devices and risk of melanoma, a recent population-based case-control study was performed in Minnesota. More than $1000 \mathrm{MM}$ cases and a similar control group were included, and $62.9 \%$ of cases and $51.1 \%$ of controls had tanned indoors (adjusted OR: 1.74; 95\% CI: 1.42-2.14). Melanoma risk was pronounced among users of UVB-enhanced (adjusted OR: 2.86 ; 95\% CI: 2.03-4.03) and primarily UVA-emitting devices (adjusted OR: 4.44; 95\% CI: 2.45-8.02). Risk increased with use: years $(P<0.006)$, hours $(P<0.0001)$, or sessions $(P=0.0002)$. The study did not include BCC and SCC lesions. ${ }^{47}$ In a study of 106,366 women with complete follow-up through 2005, $412 \mathrm{MM}$ cases were diagnosed. MM risk increased significantly with the number of sunburns and bathing vacations in the first three age decades and solarium use at ages 30-39 and 40-49 years (RR for solarium use $\geq 1$ time/month 1.49 (95\% CI: $1.11-2.00)$ and 1.61 (95\% CI: 1.10-2.35)), respectively. Risk of melanoma associated with sunburns, bathing vacations, and solarium use increased with accumulating exposure across additional decades of life. ${ }^{48}$ Within the limitations of current study design and UV dosimetry, it would therefore appear that a substantial case can be made suggesting that any use of tanning beds constitute an independent and significant factor in the development of primarily MM and SCC.

Regulating tanning bed use is apparently easier to do than controlling sun exposure. Hence, controlling tanning bed use does not suffice in preventing UV-induced skin cancer, and accordingly, the incidence of MM started to increase decades prior to the increasing popularity of tanning beds since the $1970 \mathrm{~s}^{49}$

\section{Other side effects of tanning beds Burns}

The acute burn damage caused by tanning beds can be serious and has been described in at least one UK center. ${ }^{50}$ Though not frequent, it is in itself alarming as even a serious burn in a tanning bed apparently does not lead to greater caution or interruption of tanning bed use among some users. ${ }^{51}$ Primarily, the malfunction of tanning facilities leading to excess UV light and serious burns does however identify a lack of attention, not only in the users but also in the companies responsible for the provision and maintenance of the equipment. ${ }^{52}$ It has been suggested that a significant proportion of the providers do not adhere to British or European standards for UV radiation, and that 4 out of 5 tanning beds exceeded the limit specified in these standards. ${ }^{9}$ Furthermore, there has been a significant increase in UV radiation from tanning beds since $1988 .{ }^{9}$

\section{Bacteria}

Tanning beds host a substantial microbial flora. A study investigated the microbiological environment of the tanning salons by obtaining cultures from the tanning beds in 10 top-rated tanning salons in New York City to determine the sanitary status of the tanning beds. Several skin pathogenic cultures were found: Pseudomonas aeruginosa and Pseudomonas putida (5/10), Bacillus spp. (5/10), Klebsiella pneumonia (4/10), Enterococcus sp. (3/10), Staphylococcus aureus (3/10), and Enterobacter cloacae (2/10). ${ }^{53}$ This is of some concern for tanning bed users with, for example, atopic dermatitis or other skin barrier defects.

\section{Vitamin D issues}

Tanning bed proponents cite the health benefits of vitamin D to support indoor tanning, including concerns that reduced vitamin D levels or certain vitamin D receptor polymorphisms may be associated with increased incidence of various cancers, including melanoma. Health benefits of vitamin D can be fully dissociated from the UV exposure risks with oral vitamin $\mathrm{D}$ supplementation or from adding vitamin D-rich foods to the diet, although optimal levels remain to be established. ${ }^{11}$

\section{Cultural differences}

To aim anti-tanning bed campaigns efficiently, the groups that use tanning facilities must be described ${ }^{1}$ and the awareness of the health hazard of tanning beds in the different groups must be described. ${ }^{54}$ It seems that the general tendency in several countries such as the UK, ${ }^{20,55}$ France, ${ }^{39,56}$ Italy, ${ }^{51}$ Sweden, ${ }^{57,58}$ Germany, ${ }^{59}$ Belgium, ${ }^{56}$ The Netherlands, ${ }^{39}$ Denmark, ${ }^{30,60}$ Chile, ${ }^{61}$ Australia, ${ }^{2,8}$ Canada, ${ }^{62}$ New Zealand, ${ }^{8,63}$ and the $\mathrm{US}^{3,19,64-69}$ is that tanning beds are used primarily by young Caucasian middle- to lower-class adolescents, mainly female, and mainly for cosmetic purposes. In a large US study, tanning bed use increased from 7\% among 14-year-old girls to $16 \%$ by age 15 , and more than doubled again by age 17 to $35 \%{ }^{3}$ A systematic review of tanning bed users describe the typical sunbed user as female, between 17 and 30 years old, who tends to live a comparatively unhealthy lifestyle: users smoke cigarettes and drink alcohol more frequently and eat less healthy food than nonusers. Users are characterized by a lack of knowledge about health risks of UV light and are prompted by the frequent use of sunbeds by friends or family members and the experience of positive emotions and relaxation by indoor tanning. ${ }^{1}$ A German study revealed the worrying misconception that tanning is healthy. Frequent tanners reported that they believed that artificial UV radiation 
had a healthy effect on the skin compared to natural UV radiation. ${ }^{59}$ In a study of health-care workers in the UK, the frequency of using tanning beds was found to be negatively correlated with the age of respondents and the existence of family experience with skin cancer, and strongly associated with the opinion that it is safer to use a sunbed than sunbathing outdoors, female gender, and smoking. ${ }^{55}$ Another study also showed that smoking was a strong predictor for tanning bed use among females. ${ }^{70}$ This raises an important issue about targeting information at this group of young women who are combining two well-known carcinogens. Furthermore, youth tanning attitudes, parental indoor tanning use, and parents' permission is strongly associated with youth use of indoor tanning, ${ }^{71}$ and therefore campaigns should also change the parental attitude toward tanning.

\section{Addiction to tanning}

In epidemiological studies of tanning bed users, it has been shown that it is not always the tan per se that promotes the tanning seeking behavior - it is also the warmth of the sunbed and a general sense of well-being. ${ }^{10}$ Accordingly, if tanners crave heat, they could potentially exchange tanning with a sauna. The tanning habits of sauna users have never been described to the best of our knowledge. However, saunas are particularly popular in less sunny places. If tanning bed use were primarily aimed at obtaining a tan, however, sunless tanning products would provide an excellent solution. A small study did demonstrate that sunless tanners deliberately spent less time in the sun to $\tan .{ }^{72}$ However, another study raised the possibility that sunless tanning products did not decrease rates of sunburning or use of tanning beds. ${ }^{64}$ Thus, substitution may not be a viable path to behavior modification if the substitute addiction is not independent of the primary harmful addiction, but the two are associated, for example, cannabis and alcohol. ${ }^{73}$

\section{Clinical guidelines}

As long as tanning beds are available to the public, there is a need for guidelines and/or legislation to reduce the risks associated with their use. WHO encourages governments to formulate and enforce effective laws governing the use of tanning beds. In 2003, WHO published a brochure entitled 'Artificial tanning beds: risks and guidance' providing advice to the public, operators of tanning bed facilities, and member states on how tanning beds could be managed to protect public health. ${ }^{21}$ WHO recommended a restriction of use of tanning beds by persons under 18 years as well as banning of unsupervised facilities. WHO recommendations are consistent with those of the International Commission on Non-Ionizing Radiation Protection (ICNIRP) ${ }^{74}$ and the European Society for Skin Cancer Prevention (EUROSKIN). ${ }^{75}$ In its 2003 publication, ICNIRP recommends against the use of UV-emitting appliances for tanning or other nonmedical purposes.

\section{Patient advice}

Skin cancer poses a major public health concern, and tanning remains the most modifiable risk factor in its etiology. Primary prevention behaviors against excessive UV radiation include applying sunscreen before exposure, reapplying sunscreen every $1 \frac{1}{2}-2$ hours or after swimming or sweating, dressing in protective clothing, using shade, limiting exposure during peak sun hours, and avoiding artificial sources of UV radiation such as tanning beds. Secondary prevention behaviors include screening and early detection in combination with education on the primary prevention measures. ${ }^{76}$ ICNIRP suggest that the following groups are at particularly high risk of incurring adverse health effects from UV light and therefore should be particularly counseled against the use of cosmetic tanning appliances: people who have skin phototypes I or II, children (ie, less than 18 years of age), people who have large numbers of nevi, persons who tend to freckle, individuals who have a history of frequent childhood sunburn, people who have pre-malignant or malignant skin lesions, people who have sun-damaged skin, those who are wearing cosmetics that may enhance sensitivity to UV exposure, and persons taking photosensitizing medications. Importantly, sunscreen is often used inadequately and may induce a false sense of safety in the sun or tanning bed, and it has been shown that people using sunscreen with high sun protection factor (SPF) do not burn less than those using lower SPF as sunscreen abuse may extend sun exposure duration thus allowing sun exposure behaviors that would not be possible otherwise. ${ }^{77}$ Consequently, patients must be instructed on the proper use of sunscreen.

\section{Discussion}

An increasing body of evidence supports the theory that UV light emitted by tanning beds is not only a potential carcinogen, but a clinically significant risk factor in the development of MM, SCC, and maybe BCC. Thus, the effort in preventing UV light-induced carcinogenesis is shifting from demonstrating a causative relationship between using tanning beds and developing skin cancer to the question of how to develop new strategies for public information and warning on the potential carcinogenic effect of tanning 
beds. The use of tanning devices by a substantial minority of young people is a worrying trend in terms of a likely increased incidence of $\mathrm{MM}$ and nonmelanoma cancers in the future. ${ }^{33}$

Since most tanning bed users are young middle- and lower-class adolescents and women, the anti-cancer antitanning bed campaigns must be primarily directed at these users. It does, however, appear prudent to formulate the information so that it reaches both tanning beds users and sunbathers, as these are often the same group. ${ }^{5,54,76}$

\section{Disclosure}

The authors report no conflicts of interest in this work.

\section{References}

1. Schneider S, Kramer H. Who uses sunbeds? A systematic literature review of risk groups in developed countries. $J$ Eur Acad Dermatol Venereol. 2010 Jun;24(6):639-648. Epub 2009 Dec 8.

2. O'Riordan DL, Field AE, Geller AC, et al. Frequent tanning bed use, weight concerns, and other health risk behaviors in adolescent females (United States). Cancer Causes Control. 2006;17(5):679-686.

3. Geller AC, Colditz G, Oliveria S, et al. Use of sunscreen, sunburning rates, and tanning bed use among more than 10,000 US children and adolescents. Pediatrics. 2002;109(6):1009-1014.

4. Diffey B. Sunbeds, beauty and melanoma. Br J Dermatol. 2007;157(2): 215-216.

5. Autier P. Perspectives in melanoma prevention: the case of sunbeds. Eur J Cancer. 2004;40(16):2367-2376.

6. Levine JA, Sorace M, Spencer J, Siegel DM. The indoor UV tanning industry: a review of skin cancer risk, health benefit claims, and regulation. J Am Acad Dermatol. 2005;53(6):1038-1044.

7. Hoerster KD, Garrow RL, Mayer JA, et al. Density of indoor tanning facilities in 116 large US. cities. Am J Prev Med. 2009;36(3):243-246.

8. Jopson JA, Reeder AI. An audit of Yellow Pages telephone directory listings of indoor tanning facilities and services in New Zealand, 1992-2006. Aust N Z J Public Health. 2008;32(4):372-377.

9. Oliver H, Ferguson J, Moseley H. Quantitative risk assessment of sunbeds: impact of new high power lamps. Br J Dermatol. 2007;157(2): 350-356.

10. Nolan BV, Feldman SR. Ultraviolet tanning addiction. Dermatol Clin. 2009;27(2):109-112, v.

11. Woo DK, Eide MJ. Tanning beds, skin cancer, and vitamin D: an examination of the scientific evidence and public health implications Dermatol Ther. 2010;23(1):61-71.

12. Kaur M, Liguori A, Lang W, Rapp SR, Fleischer AB Jr, Feldman SR. Induction of withdrawal-like symptoms in a small randomized, controlled trial of opioid blockade in frequent tanners. JAm Acad Dermatol. 2006;54(4):709-711.

13. Jemec GB. Primary prevention of malignant melanoma: to know may not be enough. J Am Acad Dermatol. 1993;28(5 Pt 1):799-800.

14. Matsumura Y, Ananthaswamy HN. Short-term and long-term cellular and molecular events following UV irradiation of skin: implications for molecular medicine. Expert Rev Mol Med. 2002;4(26):1-22.

15. Molho-Pessach V, Lotem M. Ultraviolet radiation and cutaneous carcinogenesis. Curr Probl Dermatol. 2007;35:14-27.

16. Kulesz-Martin M, Lagowski J, Fei S, et al. Melanocyte and keratinocyte carcinogenesis: 553 family protein activities and intersecting mRNA expression profiles. J Investig Dermatol Symp Proc. 2005;10(2): $142-152$.

17. de Gruijl FR. p53 mutations as a marker of skin cancer risk: comparison of UVA and UVB effects. Exp Dermatol. 2002;11 Suppl 1:37-39.
18. Mitchell DL, Fernandez AA, Nairn RS, et al. Ultraviolet A does not induce melanomas in a Xiphophorus hybrid fish model. Proc Natl Acad Sci U S A. 2010;107(20):9329-9334.

19. Robinson JK, Kim J, Rosenbaum S, Ortiz S. Indoor tanning knowledge, attitudes, and behavior among young adults from 1988-2007. Arch Dermatol. 2008;144(4):484-488.

20. Thomson CS, Woolnough S, Wickenden M, Hiom S, Twelves CJ. Sunbed use in children aged 11-17 in England: face to face quota sampling surveys in the National Prevalence Study and Six Cities Study. BMJ. 2010;340:c877. doi: 10.1136/bmj.c877

21. WHO. Artificial tanning sunbeds: risks and guidance. http://www.who. int/uv/publications/en/sunbeds.pdf

22. Tucker MA. Melanoma epidemiology. Hematol Oncol Clin North Am. 2009;23(3):383-395, vii.

23. Koehler MJ, Preller A, Kindler N, et al. Intrinsic, solar and sunbedinduced skin aging measured in vivo by multiphoton laser tomography and biophysical methods. Skin Res Technol. 2009;15(3): 357-363.

24. Gilchrest BA, Eller MS, Yaar M. Telomere-mediated effects on melanogenesis and skin aging. J Investig Dermatol Symp Proc. 2009;14(1): 25-31.

25. Gallagher RP, Lee TK. Adverse effects of ultraviolet radiation: a brief review. Prog Biophys Mol Biol. 2006;92(1):119-131.

26. Cox NH. Actinic keratosis induced by a sunbed. BMJ. 1994;308(6934): 977-978.

27. Salisbury JR, Williams H, du Vivier AW. Tanning-bed lentigines: ultrastructural and histopathologic features. JAm Acad Dermatol. 1989; 21(4 Pt 1):689-693.

28. Karagas MR, Stannard VA, Mott LA, Slattery MJ, Spencer SK, Weinstock MA. Use of tanning devices and risk of basal cell and squamous cell skin cancers. $J$ Natl Cancer Inst. 2002;94(3):224-226.

29. Ibrahim SF, Brown MD. Tanning and cutaneous malignancy. Dermatol Surg. 2008;34(4):460-474.

30. Faurschou A, Wulf HC. Ecological analysis of the relation between sunbeds and skin cancer. Photodermatol Photoimmunol Photomed. 2007;23(4):120-125.

31. Boyd AS, Shyr Y, King LE Jr. Basal cell carcinoma in young women: an evaluation of the association of tanning bed use and smoking. $\mathrm{JAm}$ Acad Dermatol. 2002;46(5):706-709.

32. Abdulla FR, Feldman SR, Williford PM, Krowchuk D, Kaur M. Tanning and skin cancer. Pediatr Dermatol. 2005;22(6):501-512.

33. Young AR. Tanning devices-fast track to skin cancer? Pigment Cell Res. 2004;17(1):2-9.

34. Westerdahl J, Ingvar C, Masback A, Jonsson N, Olsson H. Risk of cutaneous malignant melanoma in relation to use of sunbeds: further evidence for UV-A carcinogenicity. Br J Cancer. 2000;82(9):1593-1599.

35. Ting W, Schultz K, Cac NN, Peterson M, Walling HW. Tanning bed exposure increases the risk of malignant melanoma. Int $J$ Dermatol. 2007;46(12):1253-1257.

36. Schulman JM, Fisher DE. Indoor ultraviolet tanning and skin cancer: health risks and opportunities. Curr Opin Oncol. 2009;21(2): 144-149.

37. Coelho SG, Hearing VJ. UVA tanning is involved in the increased incidence of skin cancers in fair-skinned young women. Pigment Cell Melanoma Res. 2010;23(1):57-63.

38. Bataille V, Winnett A, Sasieni P, Newton Bishop JA, Cuzick J. Exposure to the sun and sunbeds and the risk of cutaneous melanoma in the UK: a case-control study. Eur J Cancer. 2004;40(3):429-435.

39. Bataille V, Boniol M, de Vries E, et al. A multicentre epidemiological study on sunbed use and cutaneous melanoma in Europe. Eur J Cancer. 2005;41(14):2141-2149.

40. Autier P. Cutaneous malignant melanoma: facts about sunbeds and sunscreen. Expert Rev Anticancer Ther. 2005;5(5):821-833.

41. International Agency for Research on Cancer Working Group on artificial ultraviolet (UV) light and skin cancer. The association of use of sunbeds with cutaneous malignant melanoma and other skin cancers: a systematic review. Int J Cancer. 2007;120(5):1116-1122. 
42. Gallagher RP, Spinelli JJ, Lee TK. Tanning beds, sunlamps, and risk of cutaneous malignant melanoma. Cancer Epidemiol Biomarkers Prev. 2005;14(3):562-566.

43. International Agency for Research on Cancer. IARC classification of carcinogens. http://www.ncbi.nlm.nih.gov/bookshelf/br.fcgi? book $=$ cmed6\&part $=\mathrm{A} 6679$

44. Bajdik CD, Gallagher RP, Astrakianakis G, Hill GB, Fincham S, McLean DI. Non-solar ultraviolet radiation and the risk of basal and squamous cell skin cancer. Br J Cancer. 1996;73(12):1612-1614.

45. Veierod MB, Weiderpass E, Thorn M, et al. A prospective study of pigmentation, sun exposure, and risk of cutaneous malignant melanoma in women. J Natl Cancer Inst. 2003;95(20):1530-1538.

46. Cust AE, Armstrong BK, Goumas C, et al. Sunbed use during adolescence and early adulthood is associated with increased risk of earlyonset melanoma. Int J Cancer. $2010 \mathrm{Jul} 28$. Epub ahead of print.

47. Lazovich D, Vogel RI, Berwick M, Weinstock MA, Anderson KE, Warshaw EM. Indoor tanning and risk of melanoma: a case-control study in a highly exposed population. Cancer Epidemiol Biomarkers Prev. 2010;19(6):1557-1568.

48. Veierod MB, Adami HO, Lund E, Armstrong BK, Weiderpass E. Sun and solarium exposure and melanoma risk: effects of age, pigmentary characteristics, and nevi. Cancer Epidemiol Biomarkers Prev. 2010; 19(1):111-120.

49. MacKie RM. Incidence, risk factors and prevention of melanoma. Eur $J$ Cancer. 1998;34 Suppl 3:S3-S6.

50. Hemington-Gorse SJ, Slattery MA, Drew PJ. Burns related to sunbed use. Burns. 2010;36(6):920-923.

51. Monfrecola G, Fabbrocini G, Posteraro G, Pini D. What do young people think about the dangers of sunbathing, skin cancer and sunbeds? A questionnaire survey among Italians. Photodermatol Photoimmunol Photomed. 2000;16(1):15-18.

52. Eltigani E, Matthews RN. An unusual cause of sunbed burns. Burns. 1994;20(1):87-88.

53. Russak JE, Rigel DS. Tanning bed hygiene: microbes found on tanning beds present a potential health risk. J Am Acad Dermatol. 2010; 62(1): 155-157.

54. Mogensen M, Kamp S, Jemec GB. Relevant public information about malignant melanoma. Ugeskr Laeger. 2007;169(7):616.

55. Amir Z, Wright A, Kernohan EE, Hart G. Attitudes, beliefs and behaviour regarding the use of sunbeds amongst healthcare workers in Bradford. Eur J Cancer Care (Engl). 2000;9(2):76-79.

56. Autier P, Dore JF, Lejeune F, et al. Cutaneous malignant melanoma and exposure to sunlamps or sunbeds: an EORTC multicenter case-control study in Belgium, France and Germany. EORTC Melanoma Cooperative Group. Int J Cancer. 1994;58(6):809-813.

57. Boldeman C, Branstrom R, Dal H, et al. Tanning habits and sunburn in a Swedish population age 13-50 years. Eur J Cancer. 2001;37(18): 2441-2448.

58. Branstrom R, Ullen H, Brandberg Y. Attitudes, subjective norms and perception of behavioural control as predictors of sun-related behaviour in Swedish adults. Prev Med. 2004;39(5):992-999.

59. Borner FU, Schutz H, Wiedemann P. A population-based survey on tanning bed use in Germany. BMC Dermatol. 2009;9:6.
60. Koster B, Thorgaard C, Clemmensen IH, Philip A. Sunbed use in the Danish population in 2007: a cross-sectional study. Prev Med. 2009; 48(3):288-290

61. Salomone C, Majerson D, Molgo M, de Santa María ML, Romero W. Tanning salons in Santiago, Chile: the knowledge of the staff in charge and the quality of information provided to potential clients before and after a new regulatory law. Photodermatol Photoimmunol Photomed. 2009;25(2):86-89.

62. Rhainds M, de Guire L, Claveau J. A population-based survey on the use of artificial tanning devices in the Province of Quebec, Canada. J Am Acad Dermatol. 1999;40(4):572-576.

63. Douglass HM, McGee R, Williams S. Sun behaviour and perceptions of risk for melanoma among 21-year-old New Zealanders. Aust $N Z J$ Public Health. 1997;21(3):329-334.

64. Brooks K, Brooks D, Dajani Z, et al. Use of artificial tanning products among young adults. J Am Acad Dermatol. 2006;54(6):1060-1066.

65. Moore J, Zelen D, Hafeez I, Ganti AK, Beal J, Potti A. Risk-awareness of cutaneous malignancies among rural populations. Med Oncol. 2003; 20(4):369-374.

66. Demko CA, Borawski EA, debanne SM, Cooper KD, Stange KC. Use of indoor tanning facilities by white adolescents in the United States. Arch Pediatr Adolesc Med. 2003;157(9):854-860.

67. Greene K, Brinn LS. Messages influencing college women's tanning bed use: statistical versus narrative evidence format and a self-assessment to increase perceived susceptibility. J Health Commun. 2003;8(5): 443-461.

68. Oliphant JA, Forster JL, McBride CM. The use of commercial tanning facilities by suburban Minnesota adolescents. Am J Public Health. 1994; 84(3):476-478.

69. Heckman CJ, Coups EJ, Manne SL. Prevalence and correlates of indoor tanning among US adults. J Am Acad Dermatol. 2008;58(5): 769-780.

70. Boldeman C, Jansson B, Dal H, Ullén H. Sunbed use among Swedish adolescents in the 1990s: a decline with an unchanged relationship to health risk behaviors. Scand J Public Health. 2003;31(3):233-237.

71. Cokkinides V, Weinstock M, Lazovich D, Ward E, Thun M. Indoor tanning use among adolescents in the US, 1998 to 2004. Cancer. 2009; 115(1):190-198.

72. Sheehan DJ, Lesher JL Jr. The effect of sunless tanning on behavior in the sun: a pilot study. South Med J. 2005;98(12):1192-1195.

73. Reiman A. Cannabis as a substitute for alcohol and other drugs. Harm Reduct J. 2009;6:35.

74. Health issues of ultraviolet tanning appliances used for cosmetic purposes. Health Phys. 2003;84(1):119-127.

75. Greinert R, McKinlay A, Breitbart EW. The European Society of Skin Cancer Prevention - EUROSKIN: towards the promotion and harmonization of skin cancer prevention in Europe. Recommendations. Eur J Cancer Prev. 2001;10(2):157-162.

76. Cummings SR, Tripp MK, Herrmann NB. Approaches to the prevention and control of skin cancer. Cancer Metastasis Rev. 1997;16(3-4): 309-327.

77. Autier P. Sunscreen abuse for intentional sun exposure. Br J Dermatol. 2009;161 Suppl 3:40-45.
Cancer Management and Research

\section{Publish your work in this journal}

Cancer Management and Research is an international, peer-reviewed open access journal focusing on cancer research and the optimal use of preventative and integrated treatment interventions to achieve improved outcomes, enhanced survival and quality of life for the cancer patient. The journal welcomes original research, clinical \& epidemiological

\section{Dovepress}

studies, reviews \& evaluations, guidelines, expert opinion \& commentary, case reports \& extended reports. The manuscript management system is completely online and includes a very quick and fair peerreview system, which is all easy to use. Visit http://www.dovepress.com/ testimonials.php to read real quotes from published authors. 